\title{
Blockage Testing in the NASA Glenn 225 Square Centimeter Supersonic Wind Tunnel
}

\author{
Abigail Sevier ${ }^{1}$ \\ Case Western Reserve University, Cleveland, OH 44106 \\ Dr. David Davis ${ }^{2}$ \\ NASA Glenn Research Center, Cleveland, OH 44135 \\ and \\ Mark Schoenenberger ${ }^{3}$ \\ NASA Langley Research Center, Hampton, VA 23666
}

\begin{abstract}
A feasibility study is in progress at NASA Glenn Research Center to implement a magnetic suspension and balance system in the $225 \mathrm{~cm}^{2}$ Supersonic Wind Tunnel for the purpose of testing the dynamic stability of blunt bodies. An important area of investigation in this study was determining the optimum size of the model and the iron spherical core inside of it. In order to minimize the required magnetic field and thus the size of the magnetic suspension system, it was determined that the test model should be as large as possible. Blockage tests were conducted to determine the largest possible model that would allow for tunnel start at Mach 2, 2.5, and 3. Three different forebody model geometries were tested at different Mach numbers, axial locations in the tunnel, and in both a square and axisymmetric test section. Experimental results showed that different model geometries produced more varied results at higher Mach Numbers. It was also shown that testing closer to the nozzle allowed larger models to start compared with testing near the end of the test section. Finally, allowable model blockage was larger in the axisymmetric test section compared with the square test section at the same Mach number. This testing answered key questions posed by the feasibility study and will be used in the future to dictate model size and performance required from the magnetic suspension system.
\end{abstract}

\section{Nomenclature}

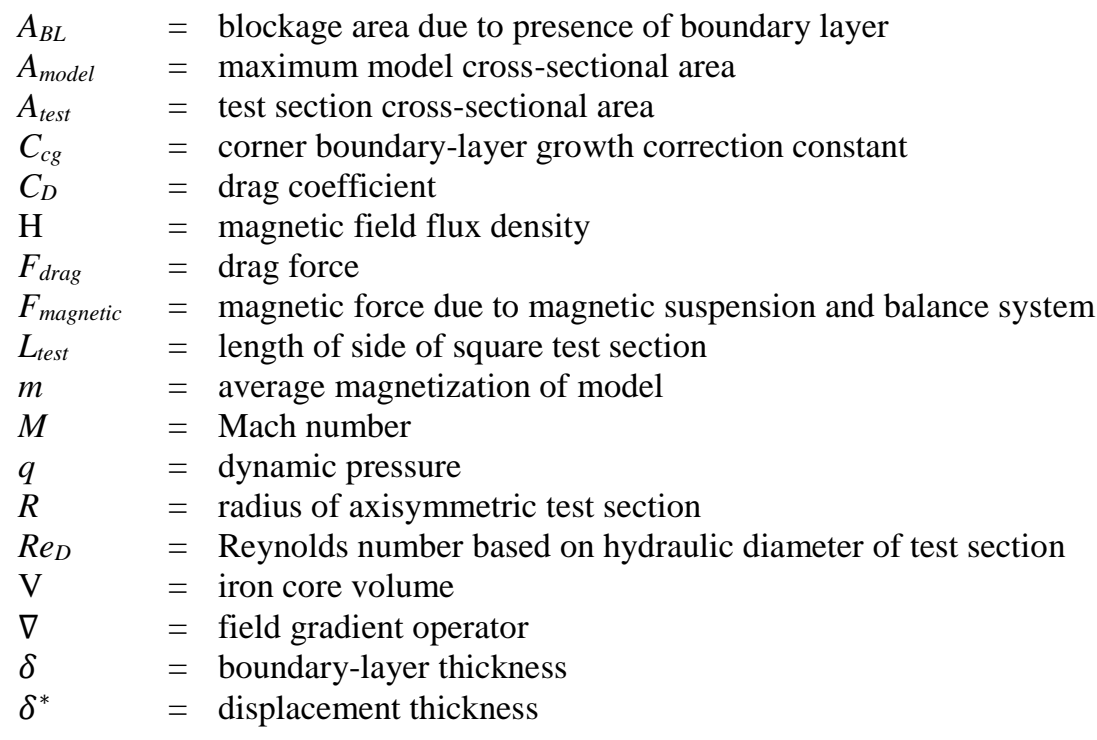

${ }^{1}$ Graduate Student, Department of Mechanical and Aerospace Engineering, AIAA Student Member.

${ }^{2}$ Aerospace Engineer, Inlets and Nozzle Branch.

${ }^{3}$ Aerospace Engineer, Entry Descent and Landing Branch, AIAA Member. 


\section{INTRODUCTION}

\section{A. Purpose}

The dynamic stability of blunt bodies during planetary entry is difficult to quantify as computational methods have yet to demonstrate accurate predictive capabilities and experimental methods cannot explicitly measure damping derivatives. Ballistic range testing has been used in the past to determine dynamic behavior of blunt body entry vehicles by firing test models from a gun down an instrumented range at low supersonic Mach numbers. Orthogonal shadowgraphs of the test model are taken during flight to measure the capsule's position and orientation. A 6 degree of freedom (6 DOF) simulation is then fit to the data points captured by the shadowgraphs and the aerodynamic coefficients are identified. Difficulties in achieving repeatable initial conditions as well as rapid changes in freestream conditions over the span of each shot presents data reduction challenges for the ballistic range test method ${ }^{1}$. In addition, the primary test range used to capture data for the Mars Science Laboratory (MSL) entry vehicle, the Aerodynamic Test and Evaluation Facility (ATEF) at the Eglin Air Force Base, was recently decommissioned. Because of these difficulties, alternative options to ballistic range testing are being explored.

One proposed alternative method to determine dynamic stability of blunt body entry vehicles is the implementation of a magnetic suspension and balance system in the NASA Glenn Research Center (GRC) $225 \mathrm{~cm}^{2}$ Supersonic Wind Tunnel (SWT). In the proposed experimental set-up, a magnetic suspension system will react against aerodynamic and gravitational forces to hold the model in a translationally fixed position in the test section, but allow the model to rotate about its center-of-mass freely so that the dynamic behavior can be observed and recorded. High-speed cameras will capture the model's position and angle of attack over time and a trajectory will be fit to these data points, much like ballistic range testing. The nearly constant freestream conditions and the elimination of significant lateral translation will improve the fidelity to which dynamic derivatives can be identified. This method has the potential to measure damping coefficients more accurately than both traditional ballistic range testing and wind tunnel testing with stings.

This project is being pursued in a parallel effort at NASA Langley Research Center (LaRC) to update an existing magnetic suspension and balance system (MSBS) originally developed by the Massachusetts Institute of Technology (MIT) which is shown in Figure 1. This MSBS was intended for use in a 6-inch low-speed wind tunnel with an octagonal cross-section. The original MSBS was designed in the late 1960s and used 6 DOF magnetic control to suspend slender cone test models. ${ }^{2}$ The models were tracked using an Electronic Position Sensor (EPS) system for position feedback which also recorded the flight dynamics of the model. This system is being updated for this project so that it can suspend blunt body models which are a much more

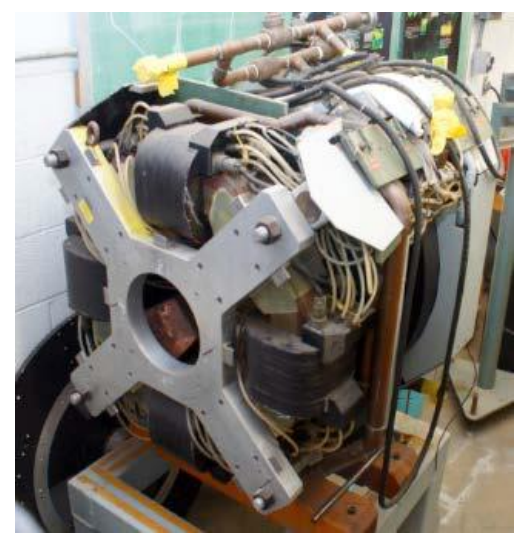

Figure 1: Magnetic Suspension and Balance System developed by MIT difficult to track optically due to their low length to diameter ratio. The concurrent project at LaRC is being approached as a pathfinder to the implementation of the scaled MSBS (which will be designed at LaRC) in the GRC $225 \mathrm{~cm}^{2}$ SWT.

The blunt body test models will be comprised of a non-magnetic material

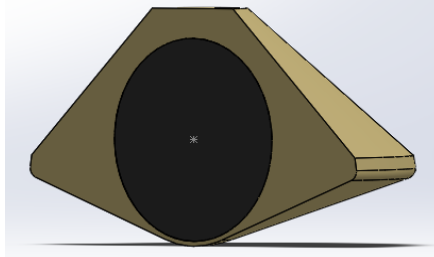

Figure 2: CAD Representation of Model with iron core surrounding a spherical iron core. The cross section of a 70-degree model is shown in Figure 2. The symmetry of the spherical iron core minimizes or eliminates magnetic moments on the model when suspended by the MSBS. This configuration, however, constrains the amount of iron material that fits within the model and the suspension system will have to be powerful enough to suspend the smaller soft iron cores. The maximum size of the model and the corresponding iron core dictates the performance requirements needed from the MSBS. It is critical, therefore, to determine the maximum model sizes and associated wind tunnel conditions over a range of Mach numbers so that the MSBS can be sized accordingly.

\section{B. Test Objectives}

The design of the MSBS must allow for the desired freestream conditions to be met while still being able to maintain control over the model's position. In order to determine the size design space for a given model geometry, the forces on the model due to drag and the magnetic suspension must be considered. Equation 1 shows the aerodynamic drag force on the model which scales with the reference area of the model, typically the maximum projected area. Equation 2 gives the magnetic force in the upstream axial direction which scales with respect to the magnetic core volume or the radius cubed. A smaller model is preferable for wind tunnel testing because drag is 
minimized, but a larger model is desirable for the MSBS. Since the magnetic force has a greater reliance on model size, it is desirable to test the largest possible model size while maintaining stable flow conditions in the wind tunnel that allow for tunnel start.

$$
\begin{gathered}
F_{\text {Drag }}=q A_{\text {model }} C_{D} \\
F_{\text {Magnetic }}=V(m \times \nabla) H
\end{gathered}
$$

Some additional objectives that were investigated during the course of testing were determining the effect of the boundary layer and the blockage it induces, the difference in model blockage at different test section locations, and the difference in model blockage between the square and axisymmetric Mach 2.5 test sections.

\section{A. Facility}

\section{METHODS}

Models of various geometries and sizes were tested in the GRC $225 \mathrm{~cm}^{2} \mathrm{SWT}$ in order to determine the maximum size for a given shape and Mach number. Test conditions of interest for this study are Mach 2, 2.5, and 3 because of the dynamic instability of blunt bodies typically observed at low supersonic speeds. The $225 \mathrm{~cm}^{2}$ SWT is a continuous flow facility with Mach number set by interchangeable fixed-geometry convergent-divergent (C-D) nozzle blocks. The facility can be configured with either a $15 \times 15 \mathrm{~cm}$ square test section or a $17-\mathrm{cm}$ round test section. The square test section has windows for schlieren capability while the round test section does not. The current supersonic Mach number capability is $\mathrm{M}=1.4$, $1.7,2.0,2.5$, and 3.0 for the square test section, and 2.5 for the round test section. The total temperature is nominally ambient. The wind tunnel is supplied with lab-wide 40 psig combustion air and exhausts to lab-wide altitude exhaust which is maintained below $13.8 \mathrm{kPa}(2.0 \mathrm{psia})$. A sketch of the $225 \mathrm{~cm}^{2} \mathrm{SWT}$ configurations is shown in Figure 3. A comparison will be drawn in particular between the blockage results between the axisymmetric and square test section configurations at Mach 2.5 to see if the difference in test section shape creates a tangible disparity between the two sets of data.
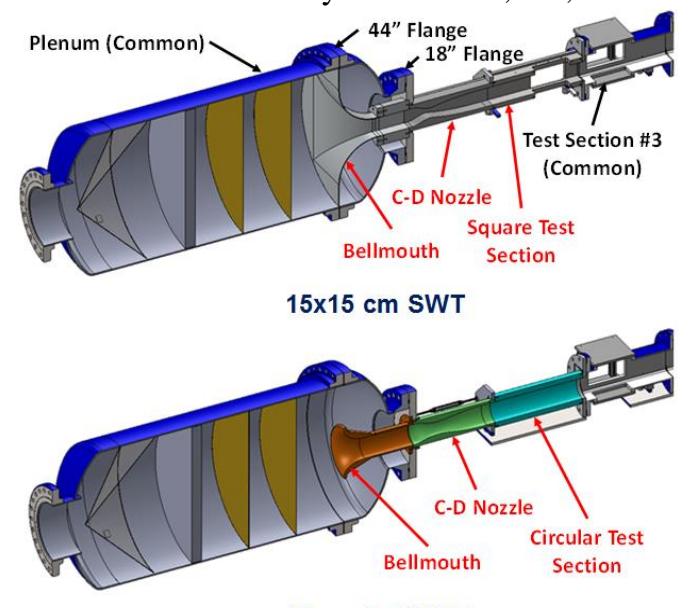

$17 \mathrm{~cm}$ Axi-SWT

Figure 3: Test Section Configuration Options

\section{B. Instrumentation}

Tunnel conditions were the main data collected during this test series. The plenum pressure was measured with a Quartz pressure transducer which needs infrequent calibrations due to its extreme precision. The total temperature in the plenum tank was calculated from the average of four type-E thermocouples. The wall pressure in the test section was measured by a series of ESP modules that record pressures upstream, downstream and at the model test location. The Electronically Scanned Pressure (ESP) system was calibrated every hour against a Quartz downhole

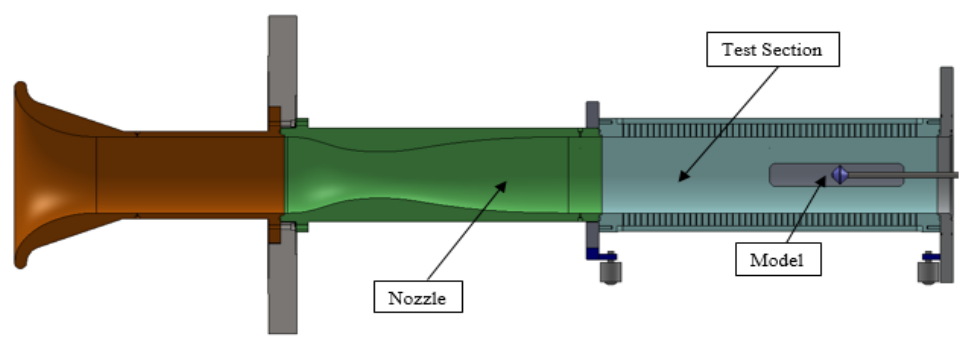

Figure 4: GRC $225 \mathrm{~cm}^{2}$ Axisymmetric Testing Set-up pressure transducer to ensure accuracy. Wall pressure taps were located at half-inch increments through the round test section and at eighth-inch increments through the square test section. The test section wall pressure distributions were used to indicate if the test section with the model installed has started. 


\section{Models}

A matrix of test models was three-dimensionally (3D) printed with varying cross sectional areas and geometries. Three different forebody geometries were chosen due to their resemblance to actual geometries flown on space missions. The chosen entry vehicles have nose cone semi-vertex angles of 45,60 , and 70 degrees which correspond to the angles often used for Venus, Earth, and Mars entries. These different angles can be observed in Figure 5.

When referring to each individual model, the first two digits correspond to the nose semi-vertex angle while the last two digits express the model's maximum area as a percent of the test section cross sectional area. For example, the 6007.5 model is 7.5 percent of the tunnel's cross-sectional area with a 60 -degree nose semi vertex angle. It was anticipated that the blunter models would have greater difficulty starting, so 70-degree cones of a given area were tested first, followed by 60 - and then 45 -degree models when possible.

A literature study was conducted to look for data or theory to

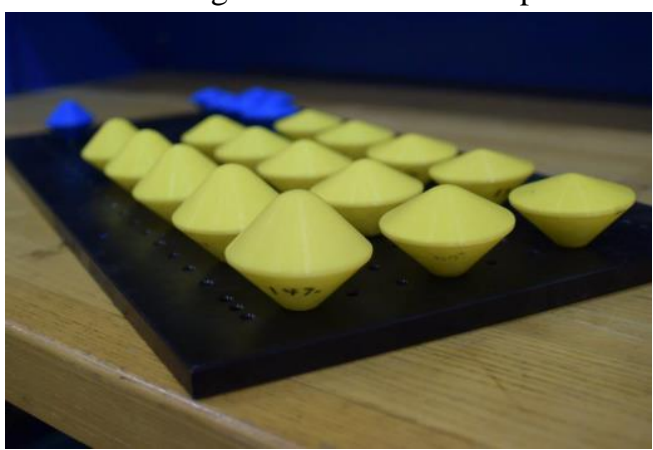

Figure 5: 3D Printed Models with Nose Cone Semi Vertex Angles of 45,60, and 70 Degrees (L-R) predict the maximum cross-sectional area. Figure 6 shows the results of this study and plots the correlation between the maximum blockage and Mach number from both wind tunnel data and empirical sources for the range of Mach 2 to 4 . The solid lines with square and circular symbols represent data taken from trend lines in the NASA GRC 1x1ft SWT user manual for both a 35- and 60-degree cone (pg 42). ${ }^{3}$ The dotted line with triangle data points plots data from the Aeronautical Systems Division (ASD) High Temperature Hypersonic Gasdynamics Facility. This set of data shows several blockage curves depending on the models drag coefficient over a large Mach number range (pg 12). ${ }^{4}$ The drag coefficient of 1.6 was chosen because it most closely represents the drag of a 70 -degree model experienced at low supersonic speeds which has a value of $1.58 .{ }^{5}$ The line with dashes and dots denotes a theoretical blockage prediction from the High-Speed Wind Tunnel Testing Handbook based on Mach number which is shown in Equation $3 .^{6}$

$$
\frac{A_{\text {model }}}{A_{\text {test }}}=1-\sqrt{5+M^{2}} \frac{\left(7 M^{2}-1\right)^{2.5}}{216 M^{6}}
$$

The dashed lines with square and circle data points show data from the LaRC $4 \mathrm{ft}$ Unitary Plan SWT. This experimental data was taken from a plot that showed a considerable range for model blockage so the lower and upper bound of this data was plotted in Figure $6 .^{7}$ The singular green diamond data point presents an extremely accurate blockage value for an isentropic compression cone at Mach 2 in the GRC $225 \mathrm{~cm}^{2}$ SWT in the square test section. Since this data was taken in the same tunnel, it was considered the most realistic value upon which to base sizing estimations.

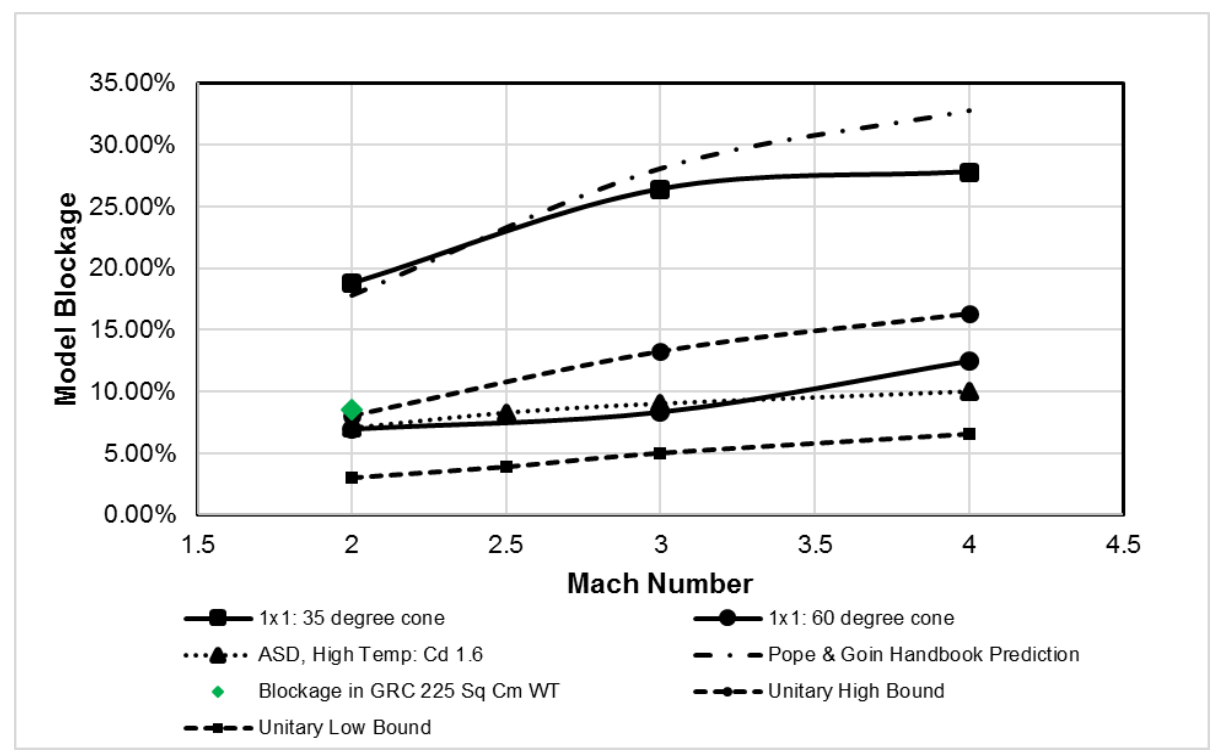

Figure 6: Literature Review Results 
The literature study was analyzed with the understanding that all of the data was taken from wind tunnels with different total pressure and flowrate capabilities. Since the data point from the GRC $225 \mathrm{~cm}^{2}$ SWT seemed to most closely align with the lower half of the data shown in Figure 6, the selection of testing areas for this study was chosen to be 4 to 14 percent at half percentage increments.

\section{Test Procedure:}

Each model was installed in the center of the test section for the test runs and was supported in the test section by a half-inch diameter steel rod. Each model has a short length of quarter-inch threaded rod epoxied into a hole in the back shell of the model (shown in Figure 7) which screws into the support rod.

For each model tested, the wind tunnel total pressure was increased gradually until the test section normal shock passed the model or until the maximum mass-flow limit ( 12 lbm/s) or total pressure (45 psi) was reached. Once a started condition occurred (if at all), the pressure was then slowly decreased to see if the tunnel could remain started at a lower total pressure. The total pressure at which the shock passed back in front of the model and the tunnel unstarted was also recorded.

Axial wall pressure distributions were examined for both the axisymmetric and square test section to determine if the model allowed for a started wind tunnel. Figure 8 shows an example of pressure distributions under unstarted and started conditions for model 6007.5 at Mach 3.0 in the square test section.

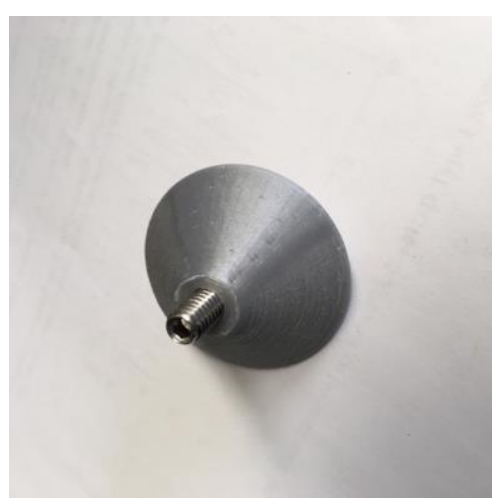

Figure 7: Backshell of Model with Epoxied Threaded Rod Figure 9 shows the corresponding schlieren images for the same capsule model shown in Figure 8. In Figure 9a, the normal shock can be seen very clearly as the flow is still attached to the models surface. In addition, the boundary layer on the tunnel walls can be seen to be very large. In Figure 9b, the tunnel has started and the bow shock sits in front of the model. The total pressure (psia) is shown in the screen legend. Note that for the unstarted case (Figure 9a), the normal shock influences the C-D nozzle exit static pressure taps leading to an indicated Mach number less than the design Mach number.

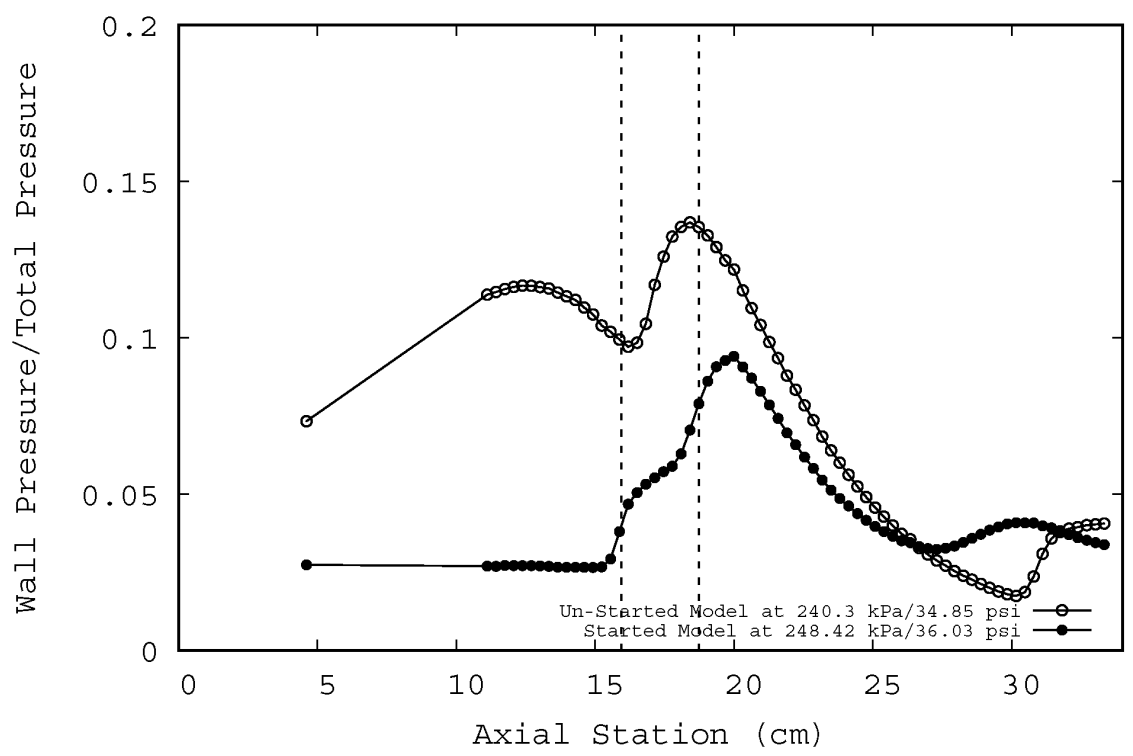

Figure 8: Pressure Tap Readings during Test for Model 6007.5 


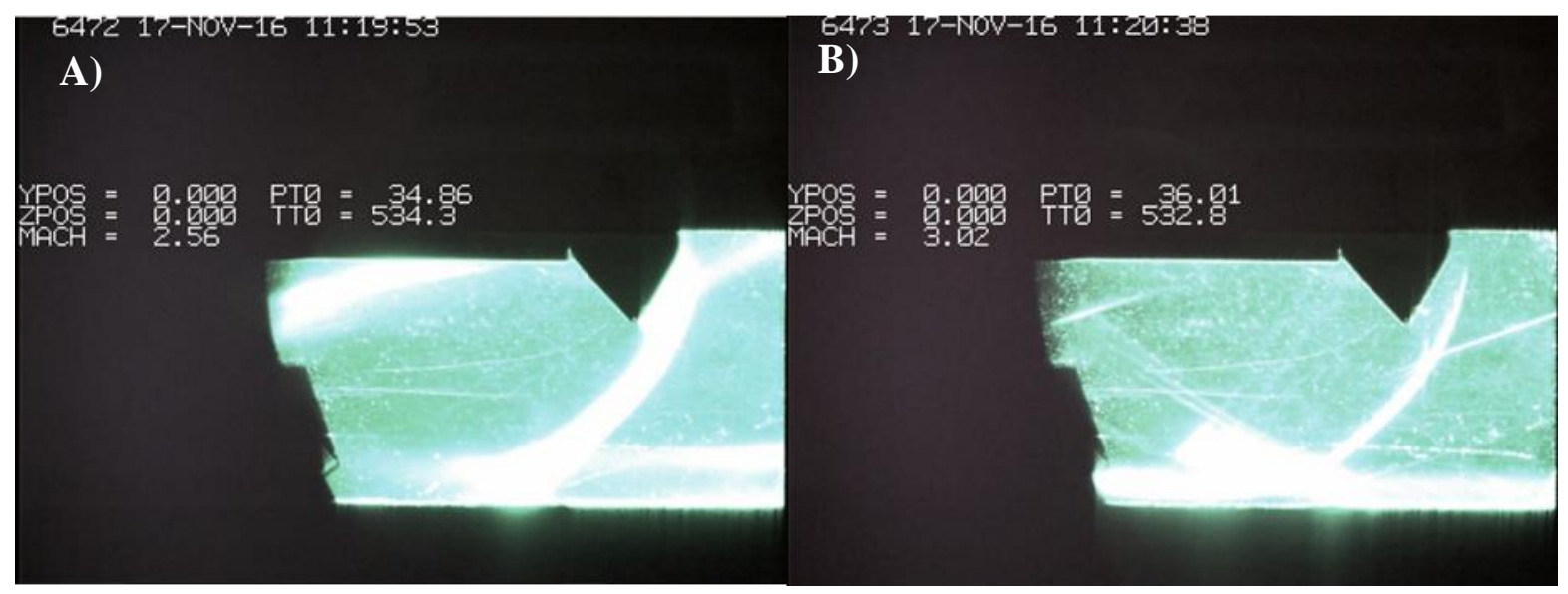

Figure 9: Schlieren Stills for Model 6007.5 just prior to SWT start (A) and after SWT start (B)

\section{RESULTS}

The following plots show the results of all blockage tests conducted during the study for this paper. The data points represent the Reynolds number based on test section hydraulic diameter $\left(\operatorname{Re}_{\mathrm{D}}\right)$ where a certain blockage model started. For each plot, a horizontal line is drawn at the top of each graph that indicates the $\operatorname{Re}_{\mathrm{D}}$ corresponding to the maximum allowable flow rate or total pressure for the tunnel. There are three sets of data on each plot, the square, circle, and triangle representing the 45-, 60-, and 70-degree models respectively. As expected, models with larger semi-vertex forebody angles proved more difficult to start. This was demonstrated by the fact that the 70degree models typically had a smaller allowable blockage or required a higher total pressure for tunnel start than the 60-degree and 45-degree models. This trend also proved true when comparing the 60-degree models to the 45 degree models.

It should be noted that the start condition was observed to not be a precise point. This is due in part to the very unsteady nature of the normal-shock/boundary-layer interaction. On occasion while sitting at an unstarted condition for some time, the shock would pass without an increase in pressure. A perturbation in the supply air or altitude exhaust due to other facilities coming online or going offline could also affect the tunnel start/unstart point.

\section{A. Mach 2.5 Nozzle Block with Axisymmetric Test Section}

Figure 10 shows the blockage and associated $\mathrm{Re}_{\mathrm{D}}$ for tunnel start for several models in the Mach 2.5 axisymmetric configuration. Models were tested at two axial locations in this configuration to help determine the significance of boundary-layer blockage variance within the length of the test section.

Figure 10a shows models that were tested at $50.8 \mathrm{~cm}$ from the nozzle which is near the back of the $58 \mathrm{~cm}$ test section. The largest 70-degree model was approximately 6 percent while the largest model size for the 45 -degree and 60-degree models was approximately 6.5 percent. Although the largest model size is the same for both the 45 degree and 60-degree cone, it can be seen that the 45-degree cone starts at a much lower $\mathrm{Re}_{\mathrm{D}}$. The blockage values corresponding to the horizontal axis are slightly less than their intended value because the axisymmetric test section has a marginally larger cross sectional area versus that of the square test section $\left(227\right.$ versus $\left.225 \mathrm{~cm}^{2}\right)$. The models were originally sized with the square test section in mind and their blockage percentage is technically less in the axisymmetric test section.

Figure 10b presents data where the model's axial testing location was moved much closer to the nozzle. The models tested at $10.2 \mathrm{~cm}$ either started right away at the lowest possible $\mathrm{Re}_{\mathrm{D}}$ or were unable to start no matter how high the total pressure was increased (the open symbol indicates an unstarted condition at the tunnel flow limit). The largest models that would start were approximately 9 percent for both a 70- and 60-degree model and approximately 10.5 percent for a 45 -degree model. The maximum model sizes seen at 10.2 centimeters are considerably larger than those seen in the blockage results taken at $50.8 \mathrm{~cm}$ from the nozzle. 

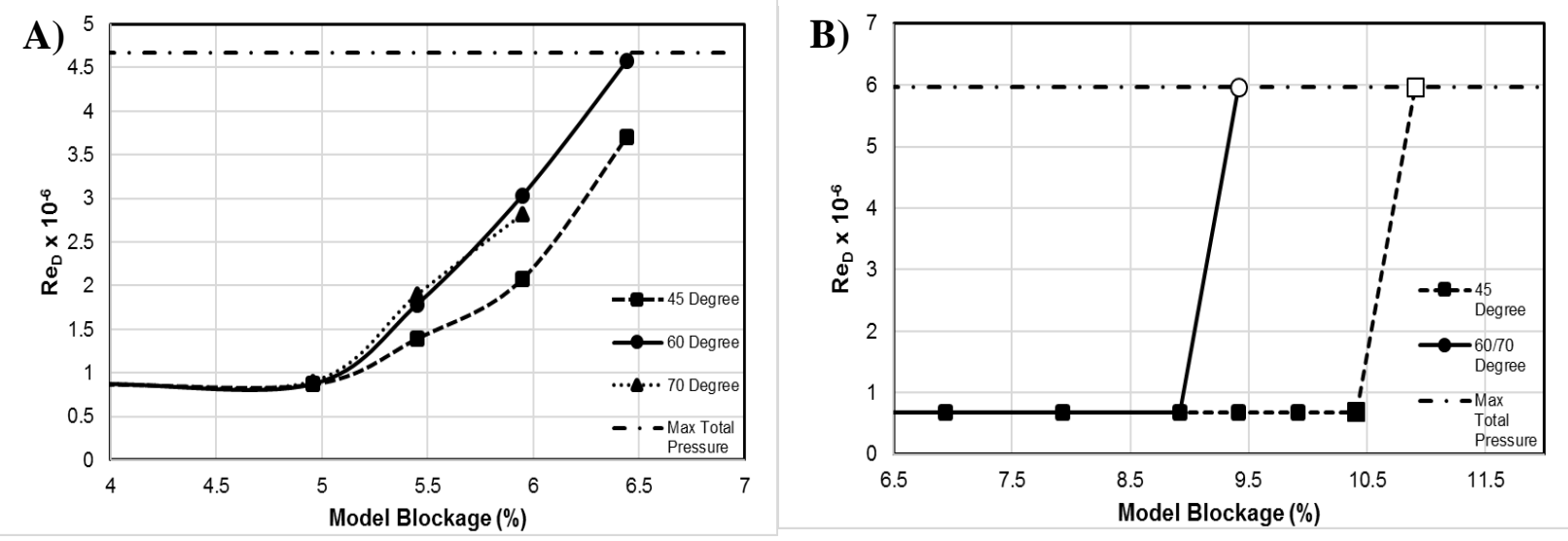

Figure 10: Mach 2.5 Axisymmetric Test Section A) $50.8 \mathrm{~cm}$ from Nozzle B) $10.2 \mathrm{~cm}$ from Nozzle

\section{Blockage Data Variation with Boundary Layer in Axisymmetric Test Section}

Figure 10 illustrates that the allowable model blockage differs considerably between 10.2 and 50.8 centimeters. One hypothesis to explain this phenomenon was that there is a substantial difference in boundary-layer blockage which would increase downstream from the nozzle. This theory was investigated to determine if the boundary-layer blockage was significant and if so, how much it differs depending on axial location.

In a previous study in the GRC $225 \mathrm{~cm}^{2} \mathrm{SWT},{ }^{8}$ the boundary layer and displacement thickness at three axial locations in the test section were measured at a $\mathrm{Re}_{\mathrm{D}}$ of $4.0 \times 10^{6}$. The measurements are shown below in Table 1 . This data was used to characterize an approximate profile for the boundary-layer growth experienced in the tunnel during blockage testing. This profile was determined by applying a quadratic fit to the three data points. This allowed the displacement thickness to be calculated at any axial location in the tunnel. The results of this quadratic fit and the corresponding equation is shown in Figure 11.

Table 1: Boundary-Layer and Displacement Thickness at Different Axial Locations

\begin{tabular}{|c|c|c|}
\hline $\mathbf{x}(\mathbf{c m})$ & $\boldsymbol{\delta}(\mathbf{c m})$ & $\boldsymbol{\delta}^{*}(\mathbf{c m})$ \\
\hline-3.81 & .608 & .161 \\
\hline 43.2 & 1.312 & .334 \\
\hline 66.0 & 1.465 & .389 \\
\hline
\end{tabular}

This data that was taken in the Mach 2.5 axisymmetric configuration at a $\operatorname{Re}_{\mathrm{D}}$ of $4 \times 10^{6}$, which is a different $\operatorname{Re}_{\mathrm{D}}$ than tested during blockage testing. Unfortunately, no information was available about the change in displacement thickness due to Reynolds number for the GRC $225 \mathrm{~cm}^{2}$ SWT axisymmetric configuration. However, another paper by Davis supplies the displacement thickness at different $\mathrm{Re}_{\mathrm{D}}$ for the same $\mathrm{SWT}$, but with the square test section

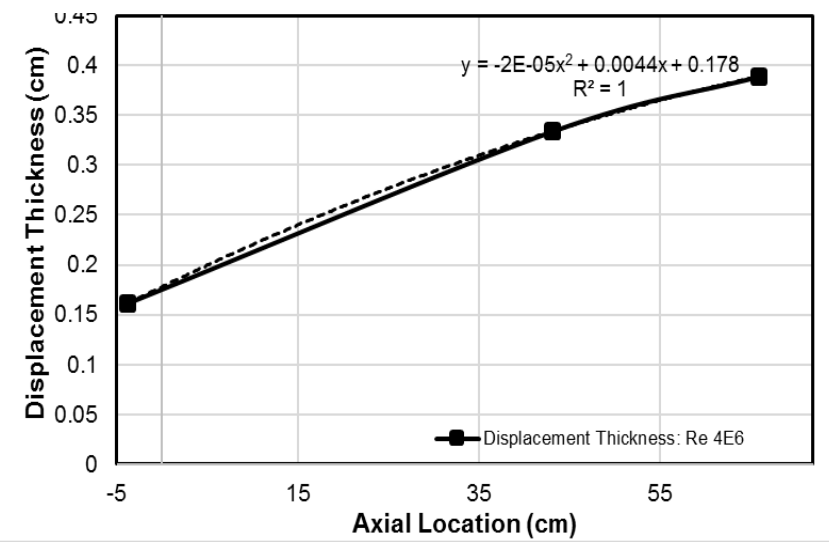

Figure 11: Quadratic Fit of Displacement Thickness in the Mach 2.5 Axisymmetric Configuration installed. ${ }^{9}$ In this paper, the displacement thickness at an axial location of $36.56 \mathrm{~cm}$ or 14.313 in was measured for 5 different Mach numbers at 3 different $\operatorname{Re}_{\mathrm{D}}$ of $1.48,2.84$ and $3.69 \times 10^{6}$. The displacement thicknesses at Mach 2.5 as well as a quadratic fit between the data points is plotted in Figure 12a. Figure 12a also shows a circular data point which represents the extrapolated displacement thickness for the axisymmetric test section at a $\operatorname{Re}_{D}$ of $4 \times 10^{6}$. This value was calculated by using the quadratic fit shown in Figure 11 which determined the resultant displacement thickness at $36.56 \mathrm{~cm}$. By comparing the displacement thickness trend line of the square test section with the extrapolated data from the axisymmetric test section, it can be seen that the displacement thickness is considerably less for the axisymmetric test section at a $\operatorname{Re}_{\mathrm{D}}$ of $4 \times 10^{6}$. 

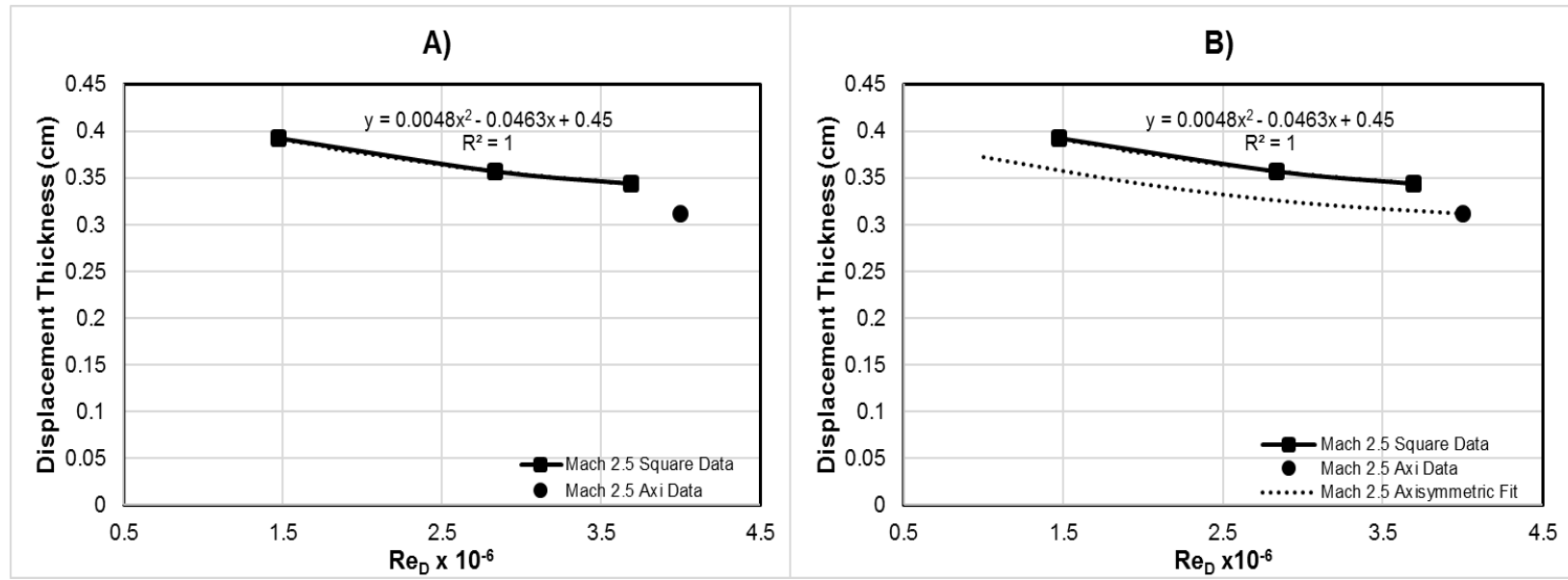

Figure 12: Mach 2.5 Reynolds Number versus Displacement Thickness at $36.56 \mathrm{~cm}$ or 14.313 in

In order to determine the relationship between $\mathrm{Re}_{\mathrm{D}}$ and displacement thickness at $36.56 \mathrm{~cm}$ for the axisymmetric test section, the quadratic fit for the square test section was scaled so that it passed through the axisymmetric data point. The results of this new scaled quadratic fit is shown in Figure $12 \mathrm{~b}$.

This new scaled quadratic fit for the axisymmetric configuration was then used to predict a potentially more accurate displacement thickness depending on the $\mathrm{Re}_{\mathrm{D}}$ each model was tested at. It must be remembered that the scaled quadratic fit gives the displacement thickness at an axial location of $36.56 \mathrm{~cm}$ rather than the actual testing locations of $10.2 \mathrm{~cm}$ and $50.8 \mathrm{~cm}$. The displacement thickness can be approximated at these testing locations by assuming the same axial boundary-layer growth shown in Figure 11 and was multiplied by a scaling factor to approximate the value at 10.2 or $50.8 \mathrm{~cm}$.

Using this approximation of the displacement thickness, the blockage due to the presence of the boundary layer can be calculated using Equation 4 for the axisymmetric test section at both testing locations. The results of this approximation are shown in Table 2 for the largest blockage model that was able to start of each geometry. The approximations used to determine the values in Table 2 are made with assumptions based on limited data in the GRC $225 \mathrm{~cm}^{2} \mathrm{SWT}$. These assumptions, while likely not exact, are enough to draw conclusions that help inform the feasibility of the MSBS.

$$
\frac{A_{B L}}{A_{\text {test }}}=\frac{2 R \delta^{*}-\delta^{* 2}}{R^{2}}
$$

Table 2: Boundary-Layer Blockage for Axisymmetric Configuration

$$
\begin{array}{llll}
\mathrm{x} 10^{6} & \mathrm{~cm} & \mathrm{~cm}
\end{array}
$$

\begin{tabular}{|cccccc|}
\multicolumn{1}{c}{ Back } & Model & $\mathbf{R e}$ & $\boldsymbol{\delta}^{*}$ at $\mathbf{3 6 . 5 6} \mathbf{~ c m}$ & $\boldsymbol{\delta}^{*}$ at $\mathbf{5 0 . 8} \mathbf{~ c m}$ & Blockage \\
\hline 70 & $6.0 \%$ & 2.822 & 0.3232 & 0.359 & $8.269 \%$ \\
60 & $6.5 \%$ & 4.573 & 0.3011 & 0.3345 & $7.715 \%$ \\
45 & $6.5 \%$ & 3.706 & 0.3089 & 0.3432 & $7.913 \%$ \\
\hline Front & Model & $\mathbf{R e}$ & $\boldsymbol{\delta}^{*}$ at $\mathbf{3 6 . 5 6} \mathbf{~ c m}$ & $\boldsymbol{\delta}^{*}$ at $\mathbf{1 0 . 2} \mathbf{~ c m}$ & Blockage \\
\hline 70 & $9.0 \%$ & 0.68 & 0.38355 & 0.2192 & $5.090 \%$ \\
60 & $9.0 \%$ & 0.68 & 0.38355 & 0.2192 & $5.090 \%$ \\
45 & $10.5 \%$ & 0.68 & 0.38355 & 0.2192 & $5.090 \%$ \\
\hline
\end{tabular}

Now that the corresponding boundary-layer blockage has been determined for each model, the total blockage due to both the boundary layer and the model can be analyzed. Table 3 shows the total blockage for the largest model of each geometry tested at $10.2 \mathrm{~cm}$ and $50.8 \mathrm{~cm}$.

Looking at the results shown in Table 3 , the agreement between the total blockage at the front and back of the test section seems to be quite close particularly in the case of the 60- and 70-degree models. This approximation strongly suggests that the presence of the boundary layer is non-negligible. Since larger models are desired for testing with the MSBS, the models should likely be tested as close to the nozzle as possible to minimize blockage 
due to the boundary layer. This also informs the recommendation that the test section can be short in length since the model should be tested close to the nozzle to minimize the boundary-layer thickness.

Table 3: Comparing Total Blockage for the Mach 2.5 Axisymmetric Configuration at 10.2 and $50.8 \mathrm{~cm}$

\begin{tabular}{|ccccc|} 
Location & Cone & Model & BL Blockage & $\begin{array}{c}\text { Total } \\
\text { Blockage }\end{array}$ \\
\hline $10.2 \mathrm{~cm}$ & 70 & $9.0 \%$ & $5.09 \%$ & $14.01 \%$ \\
$50.8 \mathrm{~cm}$ & 70 & $6.0 \%$ & $8.27 \%$ & $14.22 \%$ \\
\hline $10.2 \mathrm{~cm}$ & 60 & $9.0 \%$ & $5.09 \%$ & $14.01 \%$ \\
$50.8 \mathrm{~cm}$ & 60 & $6.5 \%$ & $7.72 \%$ & $14.16 \%$ \\
\hline $10.2 \mathrm{~cm}$ & 45 & $10.5 \%$ & $5.09 \%$ & $15.50 \%$ \\
$50.8 \mathrm{~cm}$ & 45 & $6.5 \%$ & $7.91 \%$ & $14.36 \%$ \\
\hline
\end{tabular}

\section{B. Mach 2.5 Nozzle Block with Square Test Section at $18.7 \mathrm{~cm}$}

This next set of blockage data is a significant configuration switch from the axisymmetric test section to the square test section. The axisymmetric test section had pressure taps spanning the entire test section, but unfortunately the square test section only had pressure taps along the window of the test section. Because of this, the most forward the model could be tested and still be at the axial location of a pressure tap was $18.7 \mathrm{~cm}$ or 7.375 inches from the nozzle.

The blockage testing results for the Mach 2.5 Square Test Section are very similar to that of the Mach 2.5 Axisymmetric configuration for the 60- and 70-degree models. The largest model size for both is 6 percent with the 70-degree model requiring a higher Reynolds number than the 60-degree model. The 45-degree model, however, was able to have a much larger model. It was observed that after the 6.5 percent models, the $\mathrm{Re}_{\mathrm{D}}$ between each half percent increment were very close resulting in the shallow slope seen in Figure 13. In fact, the Re $e_{D}$ were so close that models between 7 and 8.5 percent virtually had the same $\mathrm{Re}_{\mathrm{D}}$, same for 9 to 10 percent. The 10.5 percent model was tested since the models were technically starting below the mass flow and total pressure limitation, but it was lost down the tunnel due to the 3D printed material or the adhesive failing. It was decided that a significant enough drag to break the models would not be desirable for a testing environment for the MSBS system so further data wasn't needed.

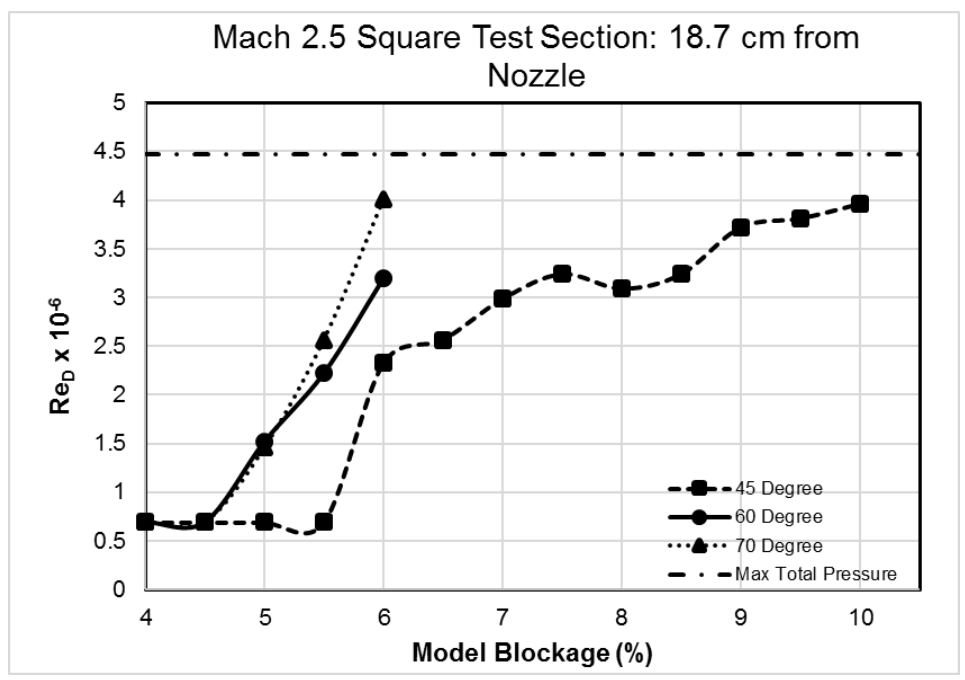

Figure 13: Blockage Plot for Mach 2.5 Square Test Section

1. Blockage Data Variation from Mach 2.5 Axisymmetric to Square Configuration

The benefits of having an axisymmetric versus square test section can be evaluated by comparing blockage data from the square and axisymmetric test section at Mach 2.5 to help determine the best test section design for the MSBS.

In order to evaluate the total blockage for the Mach 2.5 Square configuration, the boundary-layer blockage was approximated. The displacement thickness and $\mathrm{Re}_{\mathrm{D}}$ correlation shown in Figure 12 provided the displacement 
thickness at $36.56 \mathrm{~cm}$ based on the $\mathrm{Re}_{\mathrm{D}}$ at model start. However, models were tested in the square test section at $14.7 \mathrm{~cm}$. By making a similar assumption as with the axisymmetric testing locations, the displacement thicknesses were scaled by assuming the same axial growth profile shown in Figure 11. The boundary-layer blockage is calculated using the following formula shown in Equation 5.

$$
\frac{A_{B L \text { Blockage }}}{A_{\text {test section }}}=C_{C G} \frac{L_{\text {test }}^{2}-\left(L_{\text {test }}-2 \delta^{*}\right)^{2}}{L_{\text {test }}^{2}}
$$

Table 4: Total Blockage Comparison between Square and Axisymmetric Test Section

\begin{tabular}{|ccccc|}
\multicolumn{1}{c}{ Location } & Cone & Model & BL Blockage & Total Blockage \\
\hline Axi-10.2 cm & 70 & $9.0 \%$ & $5.09 \%$ & $14.01 \%$ \\
Axi-50.8 cm & 70 & $6.0 \%$ & $8.27 \%$ & $14.22 \%$ \\
Square & 70 & $6.0 \%$ & $7.87 \%$ & $13.87 \%$ \\
\hline Axi-10.2 cm & 60 & $9.0 \%$ & $5.09 \%$ & $14.01 \%$ \\
Axi-50.8 cm & 60 & $6.5 \%$ & $7.72 \%$ & $14.16 \%$ \\
Square & 60 & $6.0 \%$ & $8.09 \%$ & $14.09 \%$ \\
\hline Axi-10.2 cm & 45 & $10.5 \%$ & $5.09 \%$ & $15.50 \%$ \\
Axi-50.8 cm & 45 & $6.5 \%$ & $7.91 \%$ & $14.36 \%$ \\
Square & 45 & $10.0 \%$ & $7.88 \%$ & $17.88 \%$ \\
\hline
\end{tabular}

The exact growth of the boundary layer isn't known at the corners, so a corner growth correction constant was added to Equation 5 to account for it. No test data was available for this parameter, so it was adjusted until the total blockage matched that of the 60- and 70-degree models in the axisymmetric test section closely. This value ended up being 1.087 or approximately 8.7 percent. This adjustment is a simple approach to try and characterize a complicated phenomenon, but it agrees with the assumption that the total blockage for both test sections should be similar at Mach 2.5.

The agreement in total blockage is very good for 60- and 70-degree models (even without the corner correction,) but the values for the 45-degree model blockage are considerably different between the square and axisymmetric configuration. This difference is due likely to large model blockage results for the 45 -degree model in the square test section (shown in Figure 13.)

Table 4 shows that the boundary-layer blockage approximation for the square test section is close in magnitude to the blockage at $50.8 \mathrm{~cm}$ from the nozzle in the axisymmetric test section. This is surprising considering that the model in the square test section is tested $35 \mathrm{~cm}$ closer to the nozzle. This suggests that the square test section has significantly higher boundary-layer blockage compared with the axisymmetric test section which is likely due to the boundary-layer growth at corners and the presence of contra-rotating vortex pairs along the center of the noncontoured nozzle walls. ${ }^{10}$ These approximations and analysis suggests that an axisymmetric test section would be advantageous because it would allow for the testing of larger models due to its comparably thinner boundary layer.

\section{Mach 2 Nozzle Block with Square Test Section at $18.7 \mathrm{~cm}$}

Figure 14 shows a different $\mathrm{Re}_{\mathrm{D}}$ limit than seen with Figure 10 because the mass flow limit is reached at a much lower total pressure. The largest 70-degree and 60-degree model was a blockage of 5.5 percent although the 70degree model requires a higher total pressure. The largest 45-degree model is 6 percent of the test section area. 


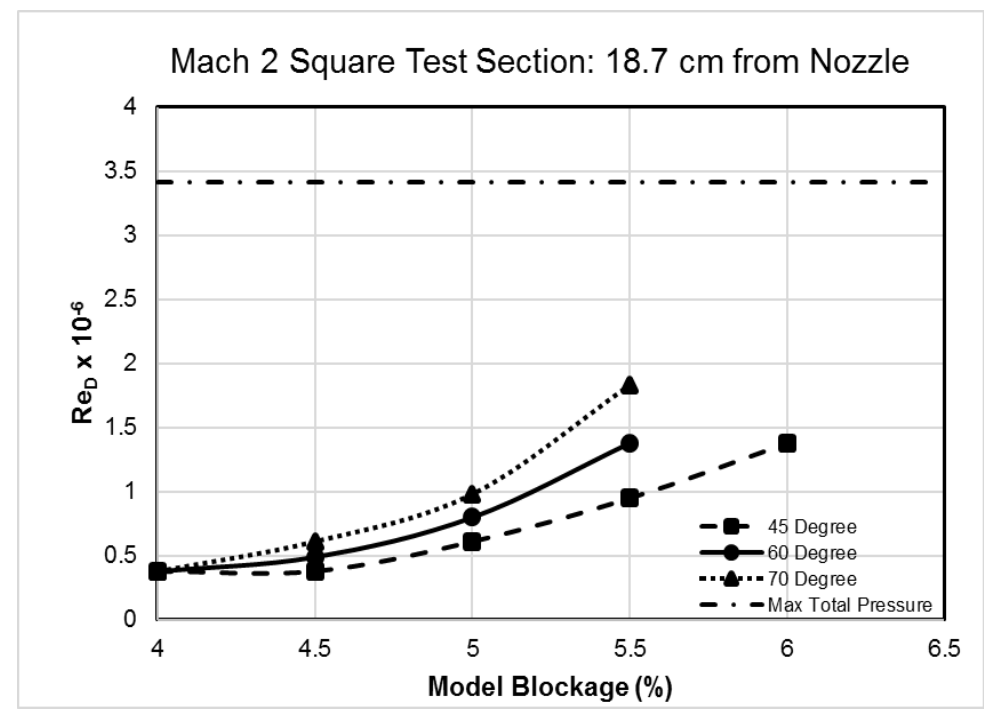

Figure 14: Blockage Plot for Mach 2 Square Test Section

\section{Mach 3 Nozzle Block with Square Test Section at $18.7 \mathrm{~cm}$}

For the Mach 3 nozzle, the upper wind tunnel limit is not dictated by mass-flow but rather supply air pressure which is limited to about 45 psia. Until the Mach 3 Square Test Section, the allowable blockage of the 60- and 70degree models was very similar with the 45-degree model being an outlier. Figure 14 depicts that the difference between the test models' semi-vertex angles causes a significant difference in allowable blockage at Mach 3 . The largest possible model size for the 70-degree model is 6 percent, the same value as seen at Mach 2.5. The 60-degree model, however, sees significantly larger blockage allowed with the step up to 8 percent from 6 percent at Mach 2.5 . Finally, the 45-degree model sees another small jump with tunnel start possible at 11 percent blockage while Mach 2.5 started with a model of 10 percent. It should be noted that an 11.5 percent model was tested for the 45 -degree model, but the model loading as the total pressure was increased caused unsteady dynamics so further testing was halted.

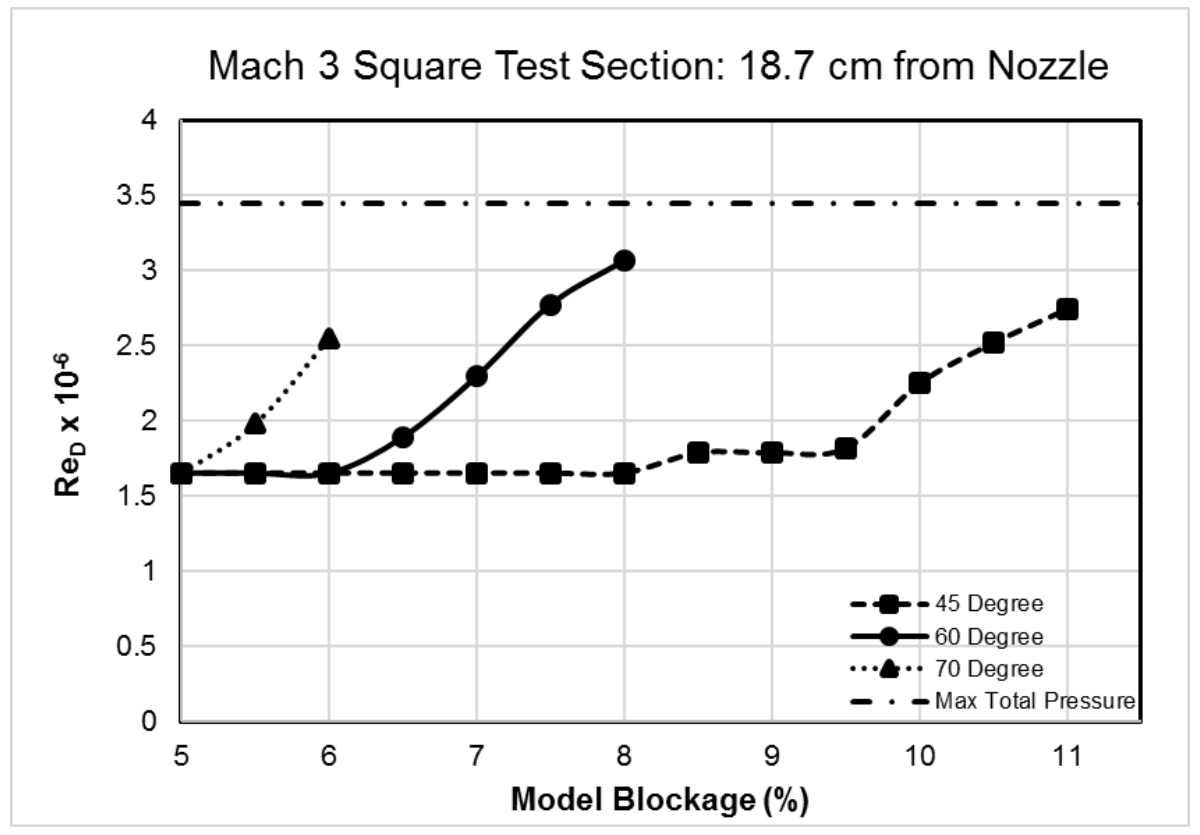

Figure 14: Blockage Plot for Mach 3 Square Test Section 


\section{E. Mach Number versus Area Relation}

Figure 15 shows the largest models of each model geometry tested in the square test section plotted on top of the original literature study. The data falls between the low and high bound for the unitary tunnel and, as expected, 70degree models have the smallest possible blockage and 45-degree models have largest possible blockage. The 60and 70-degree models have very similar blockage for Mach 2 and Mach 2.5, but diverge at higher Mach numbers. The blockage values for the 45-degree models are smaller than the potential blockage in the tunnel, but they correspond to the models successfully tested in the GRC $225 \mathrm{~cm}^{2}$ SWT.

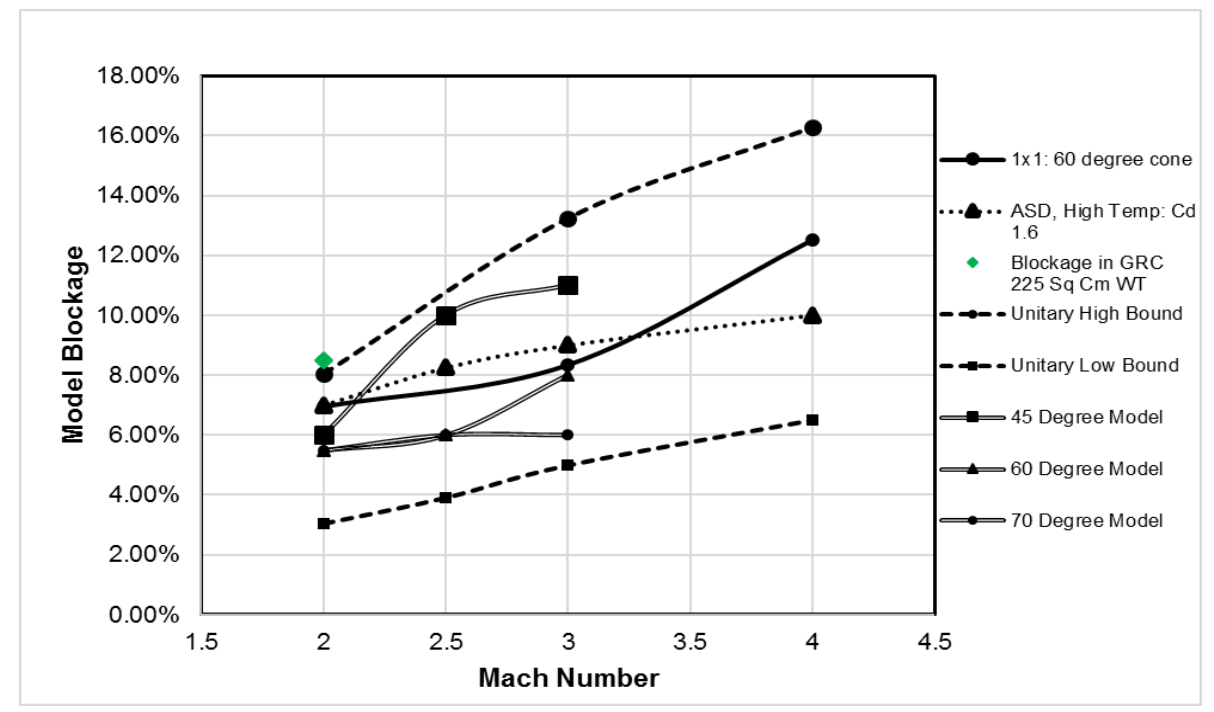

Figure 15: Literature Review with Blockage Test Data Added

The blockage data taken in this study was then re-plotted independently with a high and low bound approach which is shown in Figure 16. The blockage values at which the tunnel started right away and needed no total pressure increased were recorded as the lower bound. The upper bound used the largest blockage models that were able to start at each Mach number.

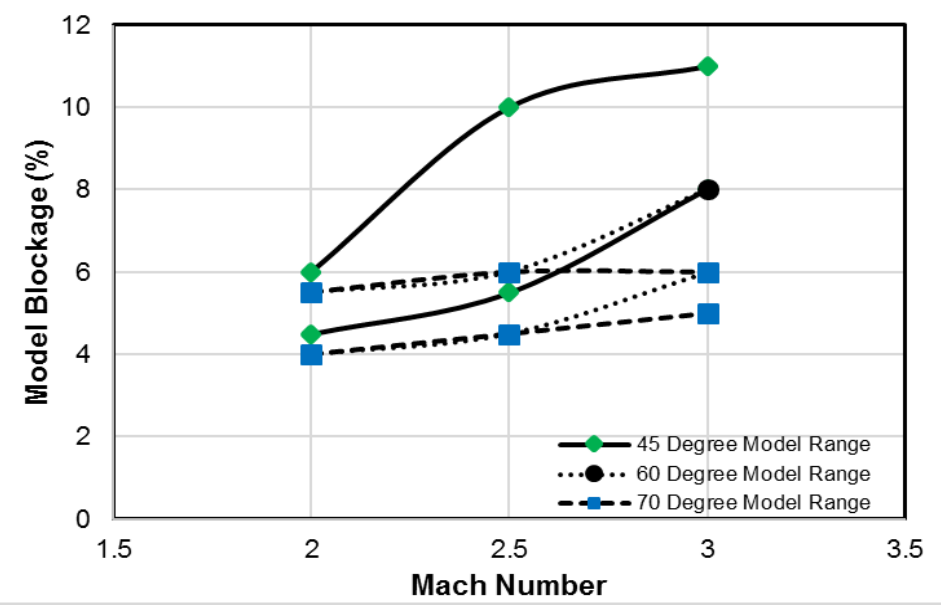

Figure 16: Blockage Study Results with High and Low Bound for Each

The 45-degree models have a large range of allowable model sizes, whereas the 70- and 60-degree models have a narrower range. As stated earlier, starting any SWT is not a precise practice and this figure will be used for approximate sizing only. However, this study has managed to confine a very open size range for models to something more manageable and more constrained. 


\section{F. Lowest Red for All Configurations}

During the course of testing it was found that once tunnel start has been achieved with a model, the SWT's Re $e_{D}$ could be decreased significantly while still maintaining supersonic flow in front of the model. This behavior is advantageous because a lower $\mathrm{Re}_{\mathrm{D}}$ results in less drag on the model which eases the performance requirements for the MSBS.

If the wind tunnel was able to start, the total pressure was decreased incrementally to see if supersonic flow could be maintained at a lower $\mathrm{Re}_{\mathrm{D}}$. The tunnel's $\mathrm{Re}_{\mathrm{D}}$ was decreased until the tunnel unstarted at which point the $\mathrm{Re}_{\mathrm{D}}$ corresponding to the last started condition was recorded. The unstart conditions are shown in Table 5. It was observed that the $\mathrm{Re}_{\mathrm{D}}$ at which the tunnel unstarted for a certain configuration was very similar regardless of model size and geometry. One exception was in the Mach 2.5 Square configuration where a much larger range $\mathrm{Re}_{\mathrm{D}}$ was seen over two days of testing several weeks apart. This demonstrated the variability of results depending on the day of testing and the associated test conditions. It also should be noted that data taken at $10.2 \mathrm{~cm}$ from the nozzle in the Mach 2.5 axisymmetric configuration is not included in Table 5 because in this configuration it was impossible to lower the total pressure since all models were already started at the minimum total pressure.

Table 5: Reynolds Numbers for Tunnel Unstart

\begin{tabular}{|c|c|}
\hline Configuration & Re $_{\mathbf{D}} \mathbf{\text { 10}}$ \\
\hline Mach 2 Square & $.56-.66$ \\
\hline Mach 2.5 Axi at 50.8 cm & $.68-.75$ \\
\hline Mach 2.5 Square & $.6-1.14$ \\
\hline Mach 3 Square & $.68-.81$ \\
\hline
\end{tabular}

\section{G. Starting Loads Analysis}

The dynamic pressure and resultant drag force at the $\mathrm{Re}_{\mathrm{D}}$ that tunnel start occurred is shown in Table 6. Only the drag on the largest model for a certain geometry in each configuration was computed since it represented the greatest magnitude that would be experienced. The drag force was calculated assuming a normal shock is present in front of the model which is a simplification of the bow shock that stands in front of a blunt body model.

Table 6: Drag on Model During Tunnel Start

\begin{tabular}{|cccccc|c|}
\hline $\begin{array}{c}\text { Test } \\
\text { Section }\end{array}$ & Mach & $\begin{array}{c}\text { Cone } \\
\text { Angle }\end{array}$ & Size & q & Cd & Fdrag \\
\hline Square & 2 & 70 & $5.5 \%$ & 19.71 & 1.58 & 38.53 \\
Square & 2 & 60 & $5.5 \%$ & 15.91 & 1.46 & 28.75 \\
Square & 2 & 45 & $6.0 \%$ & 19.71 & 1.3 & 34.59 \\
\hline Square & 2.5 & 70 & $6.0 \%$ & 20.18 & 1.58 & 43.05 \\
Square & 2.5 & 60 & $6.0 \%$ & 16.42 & 1.46 & 32.36 \\
Square & 2.5 & 45 & $10.0 \%$ & 20.53 & 1.3 & 60.05 \\
\hline Axi-50.8cm & 2.5 & 70 & $6.0 \%$ & 19.60 & 1.58 & 41.80 \\
Axi-50.8cm & 2.5 & 60 & $6.5 \%$ & 21.72 & 1.46 & 46.37 \\
Axi-50.8cm & 2.5 & 45 & $6.5 \%$ & 17.64 & 1.3 & 33.53 \\
\hline Axi-10.2cm & 2.5 & 70 & $9.0 \%$ & 3.23 & 1.58 & 10.34 \\
Axi-10.2cm & 2.5 & 60 & $9.0 \%$ & 3.23 & 1.46 & 9.55 \\
Axi-10.2cm & 2.5 & 45 & $10.5 \%$ & 3.23 & 1.3 & 9.92 \\
\hline Square & 3 & 70 & $6.0 \%$ & 10.14 & 1.58 & 21.63 \\
Square & 3 & 60 & $8.0 \%$ & 12.52 & 1.46 & 32.91 \\
Square & 3 & 45 & $11.0 \%$ & 10.95 & 1.3 & 35.24 \\
\hline
\end{tabular}


The drag experienced during tunnel start is very large and will likely be out of the performance capability of the MSBS. It was discussed earlier in the paper that immediately after the tunnel start, the $\operatorname{Re}_{\mathrm{D}}$ can be reduced greatly to values seen in Table 5 for each configuration. The drag on the models shown in Table 6 was recalculated for a lower total pressure that would greatly reduce the dynamic pressure, but still be large enough so that the tunnel unstarting isn't a concern. The estimated total pressure corresponding to the reduced dynamic pressure was determined to be $48.2 \mathrm{kPa}(7 \mathrm{psi})$ for the Mach 2 square configuration, $62.05 \mathrm{kPa}(9 \mathrm{psi})$ for both the Mach 2.5 square and axisymmetric configuration, and $82.74 \mathrm{kPa}(12 \mathrm{psi})$ for the Mach 3 configuration. The new drag for steady state tunnel operation is shown in Table 7.

Table 7: Drag on Model During "Steady State" Tunnel Operation

\begin{tabular}{|cccccc|c|}
\hline $\begin{array}{c}\text { Test } \\
\text { Section }\end{array}$ & Mach & $\begin{array}{c}\text { Cone } \\
\text { Angle }\end{array}$ & Size & q & Cd & Fdrag \\
\hline Square & 2 & 70 & $5.5 \%$ & 6.477 & 1.58 & 12.66 \\
Square & 2 & 60 & $5.5 \%$ & 6.477 & 1.46 & 11.70 \\
Square & 2 & 45 & $6.0 \%$ & 6.477 & 1.3 & 11.37 \\
\hline Square & 2.5 & 70 & $5.5 \%$ & 4.767 & 1.58 & 10.17 \\
Square & 2.5 & 60 & $5.5 \%$ & 4.767 & 1.46 & 9.40 \\
Square & 2.5 & 45 & $6.5 \%$ & 4.767 & 1.3 & 13.94 \\
\hline Axi-50.8cm & 2.5 & 70 & $6.0 \%$ & 4.767 & 1.58 & 10.17 \\
Axi-50.8cm & 2.5 & 60 & $6.5 \%$ & 4.767 & 1.46 & 10.18 \\
Axi-50.8cm & 2.5 & 45 & $6.5 \%$ & 4.767 & 1.3 & 9.06 \\
\hline Axi-10.2cm & 2.5 & 70 & $9.0 \%$ & 4.767 & 1.58 & 15.25 \\
Axi-10.2cm & 2.5 & 60 & $9.0 \%$ & 4.767 & 1.46 & 14.09 \\
Axi-10.2cm & 2.5 & 45 & $10.5 \%$ & 4.767 & 1.3 & 14.64 \\
\hline Square & 3 & 70 & $6.0 \%$ & 3.679 & 1.58 & 7.85 \\
Square & 3 & 60 & $8.0 \%$ & 3.679 & 1.46 & 9.67 \\
Square & 3 & 45 & $11.0 \%$ & 3.679 & 1.3 & 11.84 \\
\hline
\end{tabular}

By comparing Table 6 and Table 7, the drag was greatly reduced in every case besides the models tested at 10.2 $\mathrm{cm}$ from the nozzle in the Mach 2.5 Axisymmetric configuration. The values presented in Table 7 are well within the performance requirements of current original MIT MSBS which is promising for the feasibility of the future magnetic suspension system design. ${ }^{11}$ A likely solution to mitigate the high drag seen at tunnel start is the use of a support sting during tunnel start that could be removed once the dynamic pressure was reduced to steady-state operating conditions.

\section{CONCLUSIONS}

The first step to determine the feasibility of the magnetic suspension system in the GRC $225 \mathrm{~cm}^{2}$ SWT was defining the allowable size of the model. The model's size should be as large as possible so that the magnetic field and amperage required by the MSBS can be minimized. However, the model also must be small enough to allow for tunnel start. This allowable blockage is affected by the model geometry, axial testing location, and $\mathrm{Re}_{\mathrm{D}}$ for a certain Mach number. A test matrix of models was tested in a Mach 2, 2.5, and 3 configurations with a square test section and a Mach 2.5 configuration with an axisymmetric test section.

Several important conclusions were determined as a result of this testing. First, the model should be tested as close as possible to the nozzle. By comparing blockage data at 10.2 and $50.8 \mathrm{~cm}$ in the Mach 2.5 Axisymmetric configuration, it was determined that the boundary-layer growth downstream is significant and adversely affects the allowable model blockage. Secondly, the blockage results from the axisymmetric and square test section at Mach 2.5 were compared. By using data from two different former studies in the GRC $225 \mathrm{~cm}^{2} \mathrm{SWT}$, the boundary-layer blockage in the square test section and axisymmetric test section was approximated. The approximated boundarylayer blockage in the square test section was determined to be similar in magnitude to the value at the back of the 
axisymmetric test section even though it was considerably closer to the nozzle. This suggests that the square test section has more significant boundary-layer blockage then the axisymmetric test section. These two results help provide the recommendation that a short length, axisymmetric test section would allow the largest model to be tested. Finally, the blockage results were compiled into a figure that compared allowable blockage over a range of Mach numbers. Although it is known that the model blockage can vary significantly from run to run, this helps determine a refined sizing estimation that will be essential when sizing models and the MSBS.

It was also discovered that the total pressure can be decreased significantly after the tunnel has started with model inside. This allows the potential for the tunnel to be run at a lower $\mathrm{Re}_{\mathrm{D}}$ than seen at model start. The drag force was calculated for the model at tunnel start and at a lower "steady-state" $\mathrm{Re}_{\mathrm{D}}$ to determine the loading on the model. It was determined that the drag at tunnel start is much greater in magnitude then steady-state and may be outside current MSBS capability. It may be advantageous to size the MSBS performance to the drag experienced at steady-state conditions and use a removable model support during tunnel start.

The current work to investigate the feasibility of a magnetic suspension and balance system would allow for inexpensive testing of blunt body capsules so that aerodynamic coefficients can be determined to an improved or similar degree of accuracy as ballistic range testing. This work also answers design questions important to create an extremely beneficial modeling tool in the GRC $225 \mathrm{~cm}^{2}$ tunnel as well as open the door to impactful innovations in magnetic suspension.

\section{ACKNOWLEDGEMENTS}

I would like to thank Dr. David O. Davis for all of his advisement and support during the course of wind tunnel testing. I would like to thank Mark Schoenenberger for advising the direction of this study and providing expertise particularly related to blunt body aerodynamics. In addition, I would like to thank Brent Seifert and Katelyn

McCormick for their help in facilitating wind tunnel runs especially when technical problems arose. Finally, I would like to thank NASA for supporting this work through the NASA Science and Technology Research Fellowship. 


\section{References}

1. Schoeneberger, M., Queen, E. M., and Litton, D., "Oscillation Amplitude Growth for a Decelerating Object with Constant Pitch Damping," AIAA Paper 2006-6148, Aug. 2006.

2. Stephens, T., "Design, Construction, and Evaluation of a Magnetic Suspension and Balance System for Wind Tunnels," NASA CR-66903, November 1969.

3. Seablom, K.D, Soeder, R. H., Stark, D.E., Leone, J. and Henry, M.W., "NASA Glenn 1- by 1-Foot Supersonic Wind Tunnel User Manual,"NASA/TM-1999-208478, April 1999.

4. Czysz, P.A., "Correlation of Wind Tunnel Blockage Data," Technical Documentary Report No. ASD-TDR-63-230, April 1963.

5. Schoenenberger, M., Queen, E.M., "Limit Cycle Analysis Applied to the Oscillations of Decelerating Blunt-Body Entry Vehicles," NATO Paper RTO-MP-AVT-152.

6. Pope, A., Goin, K. L., "High-speed Wind Tunnel Testing," Wiley, New York, 1965.

7. Jackson, C. M., Corlett, W. A., Monta, W.J. "Description and Calibration of the Langley Unitary Plan Wind Tunnel," NASA Technical Paper 1905, Hampton, VA, November 1981.

8. Davis, D. O., "CFD Validation Experiment of a Mach 2.5 Axisymmetric Shock-wave/Boundary-Layer Interaction," American Society of Mechanical Engineers-Japan Society of Mechanical Engineers-Korean Society of Mechanical Engineers (AJK), Paper AJK2015-FED, July 2015.

9. Davis, D.O., Vyas, M., Slater, J., "Research on Supersonic Inlet Bleed,” AIAA Paper 2012-0272, January 2012.

10. Mokhatari, S., Bradshaw, P., "Longitudinal vortices in wind tunnel wall boundary layers," The Aeronautical Journal Vol. 87, No. 866, 1983, pp. 233, 236.

11. Britcher, C.P., Johnson, D., "Feasibility of Dynamic Stability Measurements of Planetary Entry Capsules Using a Magnetic Suspension and Balance System,” AIAA Paper 2016-4162, July 2016. 